\title{
Redes sociais acadêmicas: as condições de existência na área das ciências da comunicação no Brasil
}

\section{Academic social networks: the conditions of existence in the area of communication sciences in Brazil}

\section{Dalton Martins}

Professor Doutor no programa de pós-graduação em Comunicação da Faculdade de Informação e Comunicação da Universidade Federal de Goiás

<dmartins@gmail.com>

\section{RESUMO}

O artigo apresenta um estudo sobre as condições de formação das redes sociais acadêmicas de colaboração aplicado a área das Ciências da Comunicação, procurando evidenciar a relação entre as práticas sociais, os regimes de verdade e o plano de imanência formado pelos relacionamentos sociais dessa área e os indicadores estruturais que permitem analisar de forma empírica a rede de coautoria dos pesquisadores. A metodologia parte de uma revisão bibliográfica de estudos de análise de redes sociais de colaboração científica em várias áreas do conhecimento e utiliza da base de dados do portal de revistas da área de Comunicação - Univerciencie.org - para analisar mais de 9.800 artigos científicos numa série histórica de 42 anos de produção. Os resultados apontam para fortes características da área de Comunicação, tais como forte fragmentação, baixo índice de colaboração e dispersão entre vários grupos.

Palavras-chave: Redes sociais. Ciências da Comunicação. Práticas sociais.

\begin{abstract}
The article presents a study on the social academic collaboration networks forming conditions applied to the area of Communication Sciences, seeking to highlight the relationship between social practices, regimes of truth and the immanence plane formed by the social relationships in this area and the structural indicators used to analyze empirically co-authoring network of researchers. The study compares the results with academic social networks from other areas of knowledge and allows highlighting the specifics of the communication area and the relationship of these factors with the own history of formation of the Communication area in Brazil at universcience. org, analyzing over 9800 scientific articles in a historic production of 42 years. The results point to strong features such as highly fragmented, low collaboration index and dispersion among various groups.
\end{abstract}

Keywords: Social networks. Communication Science. Analysis of living conditions.

\section{Introdução}

A pesquisa em redes sociais desperta interesse e fascínio pela amplitude de questões, métodos e formas de interrogar o fenômeno, tendo se tornado um objeto polissêmico, utilizado como elemento que permite transversalizar muitos estudos na área de comunicação e agregar visões interdisciplinares. No entanto, temos percebido que muitos estudos têm por preocupação descrever o que são 
as redes sociais, suas vantagens e problemas em potencial como paradigma de representação dos relacionamentos sociais, bem como descrever a estrutura de redes existentes e com isso procurar inferir padrões de relacionamento entre seus atores. De forma geral, terminam por apresentar pesquisas cujo foco se concentra em falar sobre as redes e menos sobre as condições sociais que levam à formação dessas redes e podem ser utilizadas para inferir as condições causais de sua formação.

A pergunta que nos provoca e leva à produção da presente pesquisa com foco na área das Ciências da Comunicação se origina de uma outra inquietação: estamos menos interessados no que são as redes e mais em mapear e ampliar o campo problemático sobre como se constroem essas redes. Temos aqui como hipótese que se entendermos melhor os fatores sociais que influem na constituição dos relacionamentos sociais, que levam à formação de uma rede, estaremos em melhores condições de explicar a própria rede, dado que conhecemos melhor a força que motiva, os projetos que estimulam e as situações pelas quais as relações se dão. Procurar esses fatores e problematizar a maneira de indagá-los é o que, a nosso ver, pode influenciar a maneira como entendemos as redes e mesmo a maneira como pensamos a sua construção em estratégias de ativação e produção de redes sociais.

O presente artigo procura desenvolver parte deste exercício aplicado ao campo das Ciências da Comunicação no estudo da formação de redes sociais de coautoria entre pesquisadores da área. Discutimos como ponto de partida que a produção científica em torno dos artigos é uma força social relacional que move o campo científico e deve ser considerada como um dos elementos centrais na articulação entre pessoas de uma área de conhecimento. Apresentamos em seguida como se deu a estruturação das Ciências da Comunicação no Brasil, procurando ressaltar algumas tendências já mapeadas sobre sua produção científica, de onde explicitamos alguns fatores que devem ser levados em consideração para mapear as condições de existências das redes sociais que são nosso objeto de estudo. Por fim, mostramos alguns possíveis efeitos dessas condições na formação das redes e discutimos possíveis inferências que esses resultados apresentam.

\section{A produção científica acadêmica e as Ciências da Comunicação}

A produção científica de uma determinada área do conhecimento pode ser entendida como o conjunto de estratégias e práticas, o que expressa como as estratégias são vivenciadas pelas pessoas, que a comunidade científica utiliza para a divulgação de suas pesquisas, criando e alimentando os ciclos e 
as redes de interatividade que promovem a construção, comunicação e uso da informação por parte dos pesquisadores.

A colaboração em torno da produção científica se configura, portanto, a partir das estratégias que são construídas pelos pesquisadores para esse saber-fazer-poder da ciência. No entanto, presumimos que diferentes estratégias podem ser utilizadas pelas várias áreas do conhecimento, explicitando suas singularidades e maneiras próprias de articular suas redes em torno de seus interesses políticos e sociais no seu fazer ciência. São essas diferentes estratégias, o compartilhamento, a disputa e a colaboração em torno de um objeto, mesmo que múltiplo e difuso, de pesquisa que pode nos servir como indício da formação de uma comunidade específica, dado que podemos considerar que produzem essas estratégias como forma de disputar visões, posicionamentos e sentidos em torno desse objeto em comum. Entende-se aqui que a ciência se constrói do próprio processo de produção das narrativas que lhe dão visibilidade e dos movimentos de articulação de pessoas em torno da construção dessas narrativas, seja na produção de instituições que garantam o espaço de exercício de determinadas práticas, seja na viabilização cotidiana dessas práticas, tais como as aulas, os projetos científicos, as orientações, defesas de teses e dissertações, congressos, seminários, entre tantos outros que poderíamos nomear aqui.

Uma das ideias que fundamenta uma comunidade e um determinado campo científico está ligado aos tipos de práticas que um conjunto de pesquisadores realizam. Ao desenvolverem práticas semelhantes e divergentes com foco em temas semelhantes terminam por configurar uma comunidade, que colabora e disputa discursos do que é verdade a respeito desse objeto de interesse, produzindo redes de interação para divulgação de seus trabalhos e construção de reputação em grupo, reforçando o tipo de interatividade que alimenta o jogo do desenvolvimento científico. Segundo Thomas Kuhn (2005, p. 222) "uma comunidade é formada pelos praticantes de uma especialidade científica. Estes foram submetidos a uma iniciação profissional e a uma educação similares, numa extensão sem paralelos na maioria das outras disciplinas".

Vale ressaltar, já fazendo uma primeira aproximação problemática com a área da comunicação, que não devemos entender por especialidade científica a homogeneização do conhecimento entre os seus praticantes, mas sim uma certa coesão interna, uma certa disponibilidade de um entendimento existencial que permite identificar que estamos dialogando sobre um objeto em comum mesmo que de pontos de vista bastante diferentes. Nos valemos aqui da ideia de plano de imanência do campo explicitada por Sodré (2012): 


\begin{abstract}
Mas unidade não significa homogeneização enrijecida do campo de conhecimento, e sim sua coerência interna - a interação da multiplicidade temática num plano expressivo, análogo ao que Deleuze chama de "plano de imanência" - estabelecida por conexões claras entre as linhas temáticas, assim como entre os projetos de pesquisa. Para tanto (um "tanto" que falta ao campo comunicacional) se fazem necessárias discussões teóricas integradas, sejam para concordar, seja para dissentir no plano dos argumentos (Sodré, 2012, p. 11).
\end{abstract}

Mais do que isso, a ideia de um plano de imanência está ligada, de alguma forma, à ideia de redes de conversação que conservam condutas, práticas, discursos e domínios consensuais do que faz ou não parte de seus objetos de estudos.

[...] a construção da própria existência de um campo passa, sim, por sua forma de poder, mas se vê permeada por várias outras formas de poderes de racionalidades de "regimes de verdades" de dispositivos etc., que se entrecruzam, se co-determinam, guardando ainda, certas possibilidades de autonomia (Neto, 1996, p. 132).

Aquilo que é conservado nas conversações de determinadas redes, pautam e explicitam as grandes linhas que movimentam, tencionam, definem e são definidas como o que chamamos de um campo, uma área do conhecimento ou mesmo um plano de imanência temático. Esses regimes de verdade terminam por se traduzir em práticas que determinam e são determinados pelo modo de funcionamento dessas redes de conversação. A dificuldade que se coloca é como observar a formação desses regimes e onde podemos ancorar a lente de observação da pesquisa para poder descrevê-los e ver seus efeitos através dos dispositivos que são constituídos. Temos aqui como hipótese que o modo como as relações sociais se constituem são elementos de observação que devem ser utilizados para observar esses dispositivos. Como essas relações se formam na construção de narrativas que disputam o sentido de verdade, entendemos ainda mais, que esses regimes de verdade podem também ser observados por meio do que chamamos aqui de regimes informacionais, ou seja, o conjunto de estratégias de relacionamento social colocado a serviço da produção de informações que estruturam narrativas e lhes dão o lastro e subsídio para se colocar como verdade social. Dessa maneira, colocamos as 
estratégias de produção científica de uma área do conhecimento como um regime informacional e que pode ser utilizado como ponto de observação para mapearmos as estratégias de relacionamento social e auxiliar de forma significativa na identificação dos fatores que levam a formação dessas redes de relacionamento.

Vejamos agora com qual foco e como ocorrem essas conversações no campo das Ciências da Comunicação.

O campo da comunicação, de modo geral, se compreende como um campo em construção buscando definir se há ou não uma existência explícita de seus objetos de pesquisa, seus métodos e critérios de produção científica. É uma área que se articula com outros campos do conhecimento, sendo definida pelos seus teóricos como uma verdadeira zona de articulação de conhecimentos, na forma de um campo específico, mediante dispositivos estratégicos dotados de singularidades (Neto, 1996) enfatizando as perspectivas interacionais como substância principal das pesquisas na área (Weber, Bentz e Hohlfeldt, 2002).

Os objetivos do campo procedem de diferentes quadrantes como também o discurso da Comunicação. Este, com frequência é elaborado a partir do repertório filosófico, sociológico, linguístico, semiótico ou semiológico, entre outros. A essas terminologias devemos acrescentar ainda as dos profissionais que aportam o jargão do cotidiano jornalístico, publicitário, cinematográfico, mercadológico e, recentemente, o novo dialeto do escrever/pensar pontocom (Issler, 2002, p. 80).

É bem verdade que não constituímos um corpo cognitivo homogêneo. Por isso, cabe às nossas lideranças estabelecer pontes que comuniquem o saber acumulado em cada disciplina - jornalismo, cinema, publicidade, relações públicas, semiótica, cibercultura, midiologia, comunicologia, etc. - sem deixar de nutrirem-se nos conteúdos gerados pelas humanidades para engendrar ações consentâneas com as tecnologias de ponta (Melo, 2013, p. 42).

O quanto essa articulação de conhecimentos produz unicidade ou fragmentação em termos de práticas e modos de pesquisar o objeto da comunicação é uma questão em aberto, pertencendo a um importante debate em andamento pela própria comunidade de seus pesquisadores. Maria Immacolata (2006) e Aníbal Alves (1999) retomam essa questão, argumentando 
que a área ainda se encontra, assim como desde sua origem, operando a partir de uma visão fragmentada e tecnicista de olhar para a comunicação correndo riscos de indefinição e descaracterização:

Podemos dizer que os estudos da Comunicação foram marcados desde os seus começos, entre os anos (19)20 e os (19)30, pelo paradigma de Lasswell, responsável por uma visão fragmentada e parcelar do processo de comunicação que se mantém até hoje: estudos do emissor, do canal, da mensagem e do receptor. Em cada um desses fragmentos como que houve uma "especialização" em determinados aportes disciplinares. Assim, os estudos do canal na análise tecnológica; os da mensagem na linguística e os do receptor na sociologia ou na psicologia e, mais recentemente, na antropologia (Vassalo de Lopes, 2006, p. 25).

A complexidade do processo comunicativo e a multiplicidade das suas realizações levaram a abordagens muito diferenciadas quer sob o ponto de vista teórico e metodológico quer sob o ponto de vista das práticas. A tal ponto que, em nossos dias, o campo da comunicação, de tão extenso, sincrético e ambíguo, corre riscos de indefinição e descaracterização [...]. O campo das Teorias da Comunicação apresenta-se, pois, muito vasto, com limites mal definidos, atravessados por forças contrárias que ora o revigoraram ora o enfraquecem (Alves, 1999, p. 17).

O que nos interessa dessa visão é observamos que efeitos dessa fragmentação podem ser percebidos nos padrões estruturais e dinâmicos das redes sociais da área da Comunicação. Seria essa fragmentação, essa multiplicidade um fator que pode ser observado no regime informacional de constituição da produção científica das Ciências da Comunicação?

Logo, é a partir dessa fragmentação e desse corpo cognitivo não homogêneo que a área da Comunicação articula seu repertório teórico dialogando diretamente com outras áreas, como a filosofia e a sociologia, criando espaços de análise e aplicação técnica de suas questões naquilo que considera como sendo suas áreas profissionais, como o jornalismo, a publicidade e o rádio. O que a caracteriza, mais do que seus princípios e conceitos teóricos, é, como vimos acima, um direcionamento de enfoque, uma continua busca pelas perspectivas interacionais como espaço de articulação de diferentes saberes. 
A transdisciplinaridade de modo algum significa a dissolução dos problemas-objeto do campo da comunicação nos de outras disciplinas sociais, mas a construção de articulações - intertextualidades - que fazem possível pensar os meios e as demais indústrias culturais como matrizes de desorganização e reorganização da experiência social e da nova trama de atores e estratégias de poder (Martín-Barbero, 1996 citado por Vassalo de Lopes, 2006, p. 62).

A área da Comunicação surge como essa intertextualidade, como um espaço de interação, como uma rede de conversação de pesquisadores oriundos de diferentes áreas do conhecimento com interesses em desenvolver suas pesquisas com esse enfoque nas perspectivas interacionais, sejam elas apropriadas de maneiras distintas, até mesmo antagônicas a partir das múltiplas visões que vão definindo a área. É a articulação dessa rede em sua contínua conservação de seu espaço relacional que faz surgir o campo como uma zona de articulação de conhecimentos. Toda a dinâmica de uma rede social acadêmica é acionada a partir do interesse de grupos de pesquisadores de sistematizarem suas pesquisas, disputarem recursos, verdades sobre seus objetos, criando redes de conversação que utilizam como espaço de relação os dispositivos de sistematização da informação produzidos pela comunidade acadêmica, produzindo artigos em revistas, participando em congressos, seminários, produzindo livros, produção técnica e artística, explicitando em seu fazer os regimes informacionais que se tornam pontos significativos de observação de suas práticas.

As Ciências da Comunicação acabam por utilizar vocabulários e referências de outras áreas que possuem forte conexão com seus temas de interesse, como se a área ocupasse um espaço "entre", indicando o processo ainda em construção de seu campo científico. É a essa conclusão que chegam Leydesdorff e Probst (2009, p. 9), ao analisarem as redes de citação entre revistas das áreas de Comunicação, Psicologia Social e Ciência Política, demonstrando como a área de comunicação ocupa um espaço "entre" as duas outras, tomando emprestado recursos metodológicos, conceitos e teorias de referência. $\mathrm{Na}$ figura 1, a seguir, as revistas da área de comunicação estão circuladas pelos pontilhados em vermelho. 
Figura 1. Redes de citação entre Psicologia Social, Comunicações e Ciências Políticas.

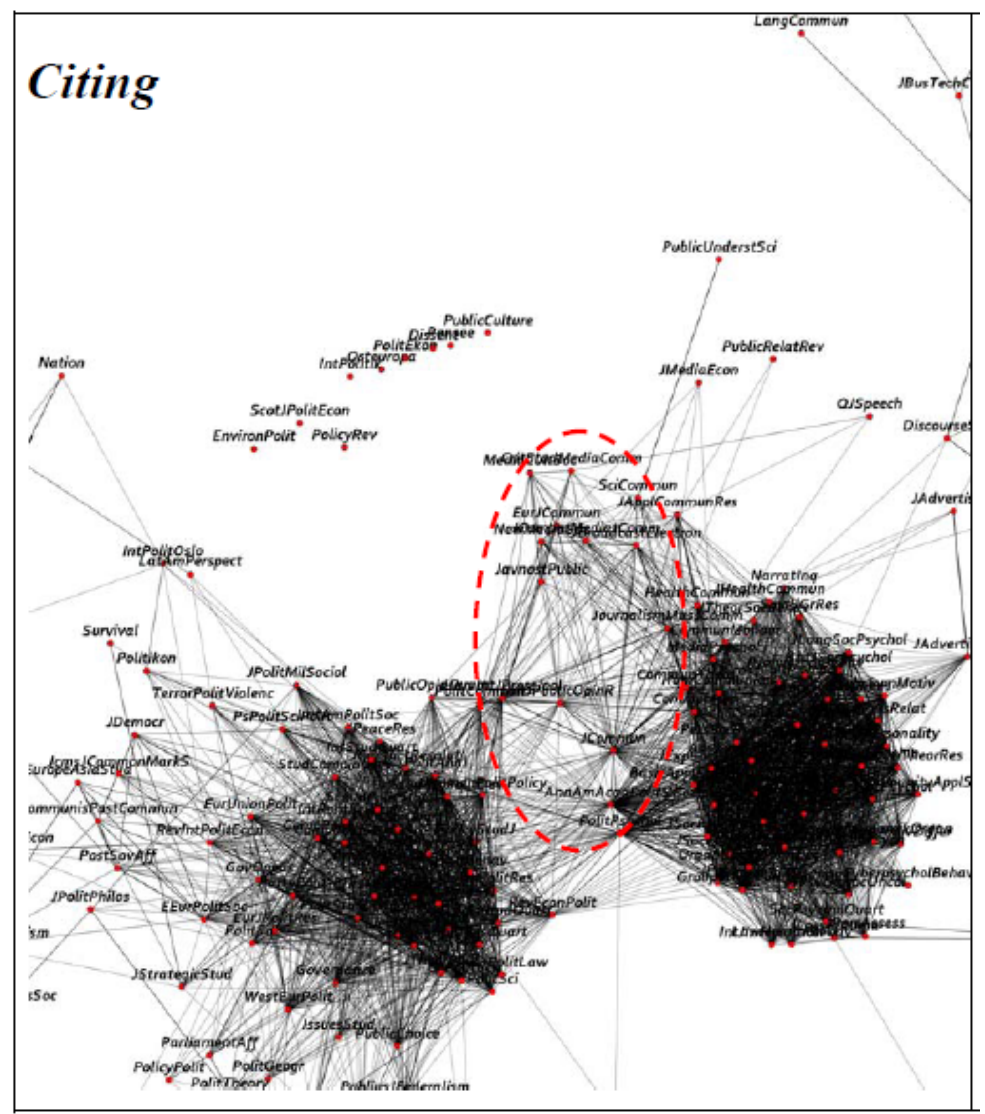

Fonte: Leydesdorff e Probst (2009, p. 7)

A figura 1 explicita, ainda em um primeiro plano de análise, o quanto o regime informacional torna-se um instrumento útil para analisar determinadas práticas e formas de relacionamento social, explicitando em partes alguns dos importantes argumentos apresentados nas citações acima: a transdisciplinaridade e intertextualidade da área da comunicação, o corpo cognitivo não homogêneo e a multiplicidade de métodos e conceitos colocados em uso.

Essa posição "entre" tem aqui uma série de implicações quando colocada em relação à visão dos pesquisadores sobre como a área funciona e se estrutura. De certa forma, estamos aqui diante de algumas evidências que nos ajudam a perceber os efeitos e produtos desse modo de funcionamento nas relações sociais estabelecidas no processo de produção científica da área.

De modo a caracterizar melhor nossa pesquisa, vejamos como as Ciências da Comunicação se encontram estruturadas e delimitadas no Brasil. 


\section{A estruturação das Ciências da Comunicação no Brasil}

As atividades de pesquisa na área das Ciências da Comunicação iniciam no Brasil a partir dos anos 1970 com a criação do primeiro programa de Mestrado na Pontifícia Universidade Católica de São Paulo (PUC/SP). Apenas dois anos depois surgem os cursos de mestrado na Universidade Federal do Rio de Janeiro (UFRJ) e na Universidade de São Paulo (USP) (Neto, 1996). Segundo os dados do relatório trienal da Coordenação de Aperfeiçoamento de Pessoal de Nível Superior - CAPES (CAPES 2009 e 2013), no ano 2000 havia 14 programas de pós-graduação em Comunicação no país, passando esse número para 63 já em 2013 , sendo destes 20 programas incluindo doutorados e 43, apenas mestrado. Vejamos na figura 2 como o número de programas se desenvolveu, onde temos um crescimento praticamente linear de 1996 até 2009, se acentuando a partir de 2006. Vale ressaltar que o documento de área das Ciências Sociais Aplicadas I de 2013 não exibe essas informações específicas para a área de Ciências da Comunicação, estando ali englobados todos os programas da área.

Figura 2. Evolução no número de programas de pós-graduação na área das Ciências da Comunicação.

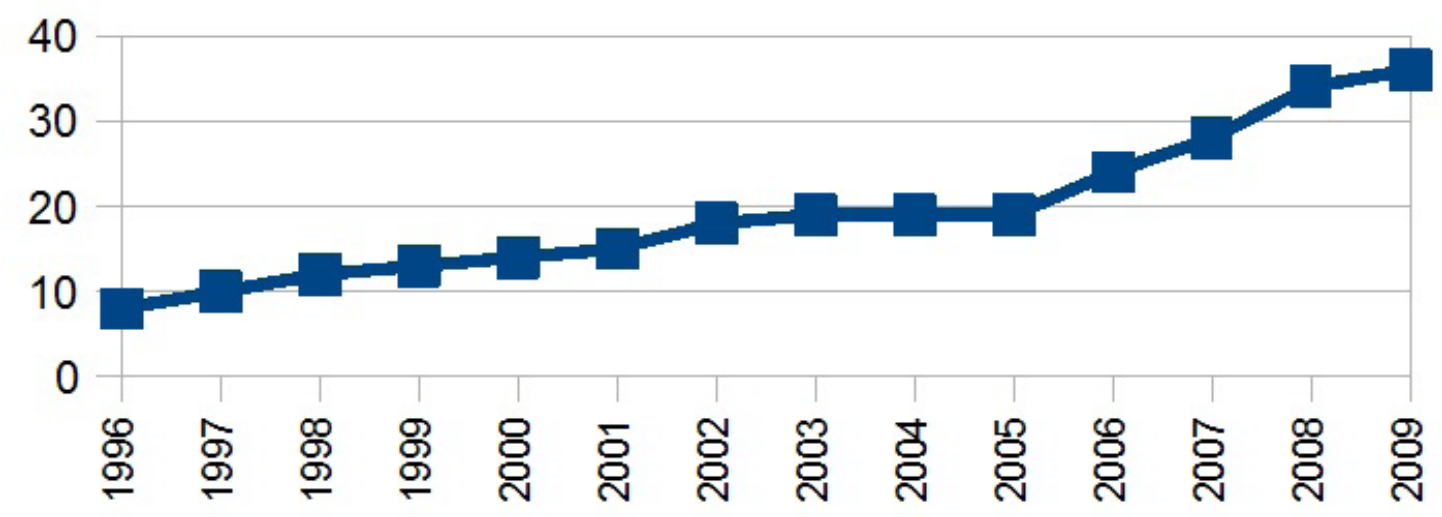

Fonte: CAPES (2009).

Deve ser ressaltado, também, o desequilíbrio na distribuição dos programas por região do país. Com efeito, dos 39 Programas existentes atualmente no Campo da Comunicação até o relatório trienal de 2009, 21 estão localizados na região Sudeste (53,8\%), sendo que, destes, 14 (35,8\%) no Estado de São Paulo; 8 (20,5\%), na região Sul; 5 (12,8\%), na região Nordeste; 3 (7,6\%), na região Centro-Oeste e 2 (5,12\%), na região Norte (CAPES, 2009). É importante ressaltar que não temos esses dados atualizados para as Ciências da 
Comunicação exclusivamente no relatório de 2013, sendo ali apresentado um panorama de distribuição da área de Ciências Sociais Aplicadas I como um todo. Entendemos que manter esses dados separados por área de conhecimento é algo de grande relevância nos documentos de área, dado que eles facilitam acompanhamentos sistematizados desses dados por pesquisas como esta que apresentamos, sendo que sua ausência dificulta o levantamento desses dados e pode gerar redundâncias de esforços.

Toffoli e Ferreira (2011, p. 403-417) ao realizarem um mapeamento da produção científica de pesquisadores brasileiros de Ciências da Comunicação no período de 2000 a 2009 trazem alguns dados que nos permitem entender melhor como a área se organiza:

- o estado de São Paulo concentra o maior número de programas: 14, no total;

- há um total bruto de 519 docentes atuando nos programas de pós-graduação, sendo 498 efetivos, 3 convidados e 14 docentes colaboradores. Há 16 docentes que figuram em mais de um programa, levando o total real de docentes para 503;

- o maior número de docentes encontra-se no Programa de PósGraduação em Comunicação (PPGCOM) da USP (46), seguido da UFRJ (27), UnB (25) e UFF (20), sendo os quatro do setor público e três deles situados na região Sudeste;

- do mapeamento da produção científica realizada, se obteve 6520 documentos categorizados como "artigos", 1772 como "livros" e 4635 "capítulos de livros";

- dos 6520 artigos identificados, 766 (12\%) foram publicados em revistas científicas internacionais, 1659 (25\%) foram publicados em revistas brasileiras de programas de pós-graduação. O restante, 4095 $(62,8 \%)$ documentos, foram publicados em outras revistas da área que não coordenados por programas de pós-graduação, publicados em revistas de outras áreas e publicados como outros tipos de documentos (resenhas, entrevistas, trabalhos apresentados em eventos, catálogo, documentos em site, etc.);

- os anos de 2007e2008 foramos mais produtivos para os pesquisadores.

Os dados acima nos permitem dizer que a área ainda apresenta uma concentração regional considerável, sobretudo na região Sudeste. Além disso, o perfil da área em termos de tipos de produção científica parece bastante 
equilibrado em termos quantitativos entre artigos (6520) e livros/capítulos de livros (6407), afirmando como tendência da área a produção tanto em artigos quanto em livros.

Em termos de enquadramento, a área de Ciências da Comunicação é vista no Brasil como Ciências Sociais Aplicadas. Vejamos como os pesquisadores da área a configuram:

No que se refere à sua área de atuação, de acordo com o CNPq e demais agências de financiamento do país, as Ciências da Comunicação estão inscritas na grande área classificada como "Ciências Sociais Aplicadas", subdividindo-se em outras subáreas tais como: comunicação visual, jornalismo e editoração, rádio e televisão, relações públicas e propaganda. Porém, tal classificação de áreas e subáreas não é ponto pacífico entre seus especialistas (Ferreira e outros, 2009, p. 154).

\begin{abstract}
Partimos da hipótese de que os estudos comunicacionais e informacionais consistem em um campo de conhecimento em construção. A base de nosso esquema cognitivo é a de estudar os fenômenos da comunicação humana, associados à produção, estocagem e difusão da informação. [...] A tradição brasileira recente vem compreendendo essa área de estudo sob a rubrica das chamadas "ciências sociais aplicadas", usando-se a nomenclatura das agências de financiamento (Lopes, 2000, p. 10).
\end{abstract}

É interessante notarmos na colocação de Ferreira e outros como as subáreas que configuram as Ciências da Comunicação refletem questões de fundo técnico, relacionando uma subárea diretamente a um tipo de mídia que vincula formatos específicos de comunicação. Essa especialização e, de certa forma, como já vimos acima, fragmentação na organização da área é um dos elementos que devemos considerar nos padrões de relacionamento entre os pesquisadores em torno de suas estratégias de produção científica. Ao que parece a especialização pela técnica acaba sendo determinante como modo de organização da área e, como imaginamos, de suas relações sociais.

Realizamos uma consulta à Tabela de Áreas do Conhecimento (CAPES, 2009) mantida pela CAPES para verificar a última versão das áreas que compõem as Ciências da Comunicação. Atualmente, fazem partes desta classificação Teoria da Comunicação, Jornalismo e Editoração, Teoria e Ética do 
Jornalismo, Organização Editorial de Jornais, Organização Comercial de Jornais, Jornalismo Especializado (Comunitário, Rural, Emp. Cientif.), Rádio e Televisão, Radiofusão, Videodifusão, Relações Públicas e Propaganda, Comunicação Visual, Programação Visual e Desenho de Produto. No entanto, como mencionado acima, a classificação da área e suas subáreas não é ponto pacífico entre as instituições e mesmo entre as publicações científicas das áreas.

Pela listagem de subáreas que vimos acima, podemos entender que o campo das Ciências da Comunicação é uma área ainda em construção, jovem e fortemente influenciada pelos aspectos técnicos das mídias que permitem operacionalizar a comunicação, sendo constituída por temas com poucas décadas de existência ainda em processo de amadurecimento de metodologias, técnicas de pesquisa, vocabulários em comum, entre outros recursos que são fundamentais para constituição de uma comunidade científica.

\begin{abstract}
A maturação e o entendimento que atingiram as chamadas ciências duras (Saúde e Tecnologia, por exemplo), quanto à necessidade de representar bem o conhecimento para recuperar eficazmente sua própria produção científica, não é equivalente em todas as áreas. Os campos das Ciências Sociais e Humanidades, dentre as quais as Ciências da Comunicação, destituídas tanto de instrumentos (vocabulários controlados e/ou tesauros) quanto de sistemas de informação específicos, vivenciam uma situação problemática frente à falta de fontes de referência terminológica para o uso de seus pesquisadores (Ferreira e outros, 2009, p. 152).
\end{abstract}

A falta desses importantes instrumentos de pesquisa e, sobretudo, de vocabulários construídos socialmente que funcionem como aglutinadores de temas de pesquisa, linhas de investigação e forneçam maior representatividade a esse plano de imanência da comunicação, sem dúvida, causa impactos que podem ser observados e devem ser considerados quando do estudo da produção científica das Ciências da Comunicação. As redes de interação são formadas e fortalecidas pelo compartilhamento do que há de comum entre os pesquisadores, ou seja, pela sua possibilidade de entender o comum no trabalho do outro que pode disparar interações de colaboração com objetivo de avanço científico, além do próprio comum que se dá no compartilhamento da linguagem de uso cotidiano no exercício das práticas e dos modos de fazer desses pesquisadores. Do contrário, as redes tendem a exibir alto grau de fragmentação, refletindo ilhas de produção de conhecimento denotando 
baixo diálogo entre si. Novamente, esse é um fator que devemos considerar na avaliação dos padrões de formação das redes sociais que analisamos nesta pesquisa. Esse comum, muitas vezes, é refletido pela terminologia e referências compartilhadas. As ciências duras, como citado acima, por serem mais antigas e já terem melhor consolidados seus recursos e metodologias de pesquisa, representam melhor seu corpo de conhecimento.

Uma das formas de formalizar conhecimentos, construir vocabulários comuns e articular pesquisadores, favorecendo o intercâmbio e a construção de repertório entre eles é o processo de institucionalização das relações sociais. A forma mais comum de se fazer na academia é por meio da criação de uma sociedade científica ou educacional. Temos na área da comunicação, segundo Melo (2013), uma constelação de 15 sociedades científicas e associações educacionais distribuídas em dois grupos. Entidades polidisciplinares (07): Sociedade Brasileira de Estudos Interdisciplinares da Comunicação - INTERCOM, Associação Nacional dos Programas de Pós-Graduação em Comunicação COMPÓS, Conferência Brasileira de Folkcomunicação - FOLKCOM, Associação Brasileira de Pesquisadores de História da Mídia - REDEALCAR, União Latina de Economia Política da Informação, Comunicação e da Cultura seção BrasilULEPIC-Brasil, Associação Brasileira de Pesquisadores em Comunicação e Política - COMPOLITICA, Associação Brasileira de Pesquisadores em Cibercultura ABCiber. Entidades mono-disciplinares (08): Associação Brasileira de Jornalismo Científico - ABJC, Sociedade Brasileira de Estudos de Cinema e Audiovisual - SOCINE, Fórum Brasileiro de Ensino de Cinema e Audiovisual- FORCINE, Fórum Nacional de Professores de Jornalismo - FNPJ, Associação Brasileira de Pesquisadores em Jornalismo - SBJor, Associação Brasileira de Pesquisadores de Comunicação Organizacional e de Relações Públicas - ABRAPCORP, Sociedade Brasileira dos Profissionais e Pesquisadores de Comunicação e Marketing Político - POLITICOM, Associação Brasileira de Pesquisadores em Publicidade ABP2.

Uma das sociedades científicas mais importantes e relevantes na área da Comunicação no Brasil é a INTERCOM. Como uma forma de criar parâmetros em comum para o desenvolvimento de pesquisas na área de Comunicação, a INTERCOM propõe um conjunto de oito divisões temáticas (DTs) que são utilizadas para orientar a divisão dos trabalhos produzidos por seus grupos de pesquisa (INTERCOM, 2011): Jornalismo; Publicidade e Propaganda; Relações Públicas e Comunicação Organizacional; Comunicação Audiovisual; Comunicação Multimídia; Interfaces Comunicacionais; Comunicação, Espaço e Cidadania; e Estudos Interdisciplinares da Comunicação. 
Outra sociedade importante da área da Comunicação é a COMPÓs (Associação Nacional dos Programas de Pós-graduação em Comunicação). A COMPÓS, já apresenta uma organização da área em 15 grupos de trabalho (GTs), que se reúnem pela ocasião de seu encontro anual, unindo, desse modo, os pesquisadores pela publicação e adesão de seus trabalhos enviados para comunicação oral e posters nestes GTs: Comunicação e Cibercultura, Comunicação e Cidadania, Comunicação e Cultura, Comunicação e Experiência Estética, Comunicação e Política, Comunicação e Sociabilidade, Comunicação em Contextos Organizacionais, Cultura das Mídias, Estudos de Cinema, Fotografia e Audiovisual, Estudos de Jornalismo, Estudos de Televisão, Epistemologias da Comunicação, Imagem e Imaginários Midiáticos, Práticas Interacionais e Linguagens na Comunicação, Recepção: processos de interpretação, uso e consumo mediáticos.

Analisando os dois modos de organização do INTERCOM e COMPÓS, percebemos diferenças significativas, sendo o primeiro mais voltado para os aspectos técnicos da área, refletindo dessa forma as subáreas que organizam a própria comunicação, já o segundo mais voltado para aspectos conceituais que determinam as interfaces e conexões que se operam a partir da comunicação.

Analisando as mais de 85 linhas de pesquisa dos principais programas no Brasil em busca de compreender como essas linhas pautam a produção científica da área, Neto (1996, p. 87) constata cinco características do campo que, reforçando o que já vimos anteriormente, irão auxiliar na análise de como operam suas redes sociais:

- há uma fragmentação do campo da comunicação numa heterogeneidade de problemas, questões e temas;

- temos a eleição de um conjunto temático de referências que fazem emergir, necessariamente, a questão da transdisciplinaridade como um desafio e, ao mesmo tempo, como uma variável essencial na eleição de procedimentos que vão nortear o desenvolvimento da pesquisa;

- também, a verticalização de interesses por temas mais abrangentes que, de uma forma ou de outra, se situariam nas fronteiras teóricas da área;

- há uma excessiva tematização de certas questões de maneira que não ficam claras as fronteiras e delimitações existentes entre elas;

- finalmente, reconhecimento de uma massa de questões a serem trabalhadas sistematicamente no conjunto de atividades dos cursos, 
cujos desembocadouros se constituem, naturalmente, as teses e dissertações.

A fragmentação do campo na variedade de temas e problemas, bem como a transdisciplinaridade, são questões que terão impactos diretos em nossa análise de como surgem e se articulam as redes sociais. A hipótese que temos é que esta fragmentação não se dá apenas nos temas, mas nas associações entre pessoas a partir de interesses fragmentados e de diferentes áreas do conhecimento. Como essas associações se formam, se articulam, que estratégias são construídas e que padrões geraram ao longo do tempo é um ponto que temos de levar em consideração.

A questão da não clareza das fronteiras temáticas é outro ponto que imaginamos ter impacto em nossa pesquisa, considerando o que já afirmamos acima que os pesquisadores se agrupam e formam comunidades a partir de redes de conversação com foco em seus objetivos de interesse. Compreender como essas fronteiras impactam nas estratégias de formação das redes é um ponto de interesse a ser explorado.

É fato que essa análise inicial da área mostra que ela ainda se encontra em fase de construção, apresentando, porém, um crescimento contínuo em termos de pessoas envolvidas, programas de pós-graduação, formas de categorização de seus objetos de pesquisa, bem como organizações que a representam. Ao que tudo indica, observamos aqui um ponto crucial e que é fundamental ressaltarmos nas palavras de Vassalo de Lopes (2006), quando caracteriza algumas das estratégias que estão em jogo nesse momento de consolidação da área das Ciências da Comunicação:

\footnotetext{
A competição que se instala num campo é, ao mesmo tempo, científica e econômica. Por um lado, à medida que crescem os recursos científicos acumulados, que se expressam nos avanços da pesquisa, aumenta o grau de homogeneidade entre os concorrentes e isso faz aumentar a competição científica. Por outro lado, o crescimento da competição científica torna mais acirrada a luta pelos recursos econômicos do campo, que já são, por definição, escassos. Identificamos claramente esse percurso percorrido pela pósgraduação no campo Comunicação (Vassalo de Lopes, 2006, p. 27).
} 
Sem dúvida, esse acirramento da competição é um dos elementos centrais desta análise que devemos levar em consideração quando da observação dos padrões estruturais e dinâmicos da formação das redes sociais da área.

\section{Tendências na produção científica}

A colaboração é também um processo em construção e ainda embrionário na área, como aponta Correa e outros (2005) num estudo realizado em sete fascículos das revistas Comunicação \& Sociedade, Contracampo, Eptic On-Line, Revista Fronteiras, Galáxia, Intercom Revista Brasileira de Ciência da Comunicação e Revista FAMECOS. Os resultados do estudo apontaram que mais de $88 \%$ dos artigos foram escritos por um único autor, numa amostra de 114 artigos coletados.

Sobre a temática da produção mapeada, Correa e outros (2005, p. 6), apresentam a tabela 1 a seguir:

\section{Tabela 1 - Distribuição temática dos artigos de 7 fascículos de revistas na área da Ciência da Comunicação.}

\begin{tabular}{|l|c|c|}
\hline \multicolumn{3}{|c|}{ Temas dos Artigos } \\
\hline \multicolumn{1}{|c|}{ Núcleos Temáticos (Intercom) } & no & $\%$ \\
\hline Teorias da Comunicação & 24 & 21,05 \\
\hline Tecnologias da Informação e da Comunicação & 18 & 15,75 \\
\hline Jornalismo & 12 & 10,53 \\
\hline Comunicação Audiovisual & 10 & 8,77 \\
\hline Relaçães Públicas e Comunicação & 7 & 6,14 \\
\hline Organizacional & 7 & 6,14 \\
\hline Políticas e Estratégias de Comunicações & 6 & 5,26 \\
\hline Semiótica da Comunicação & 5 & 7 \\
\hline Comunicação para a Cidadania & 5 & 4,39 \\
\hline Comunicação e Cultura das Minorias & 5 & 4,39 \\
\hline Comunicação e Cultura Urbanas & 4 & 4,39 \\
\hline Folkcomunicação & 3 & 3,51 \\
\hline Ficção Seriada & 2 & 2,63 \\
\hline Produção Editorial & 2 & 1,75 \\
\hline História em Quadrinhos & 2 & 1,75 \\
\hline Fotografia: Comunicação e Cultural & 1 & 1,75 \\
\hline Rádio e Midia Sonora & 1 & 0,88 \\
\hline Comunicação e Esporte & 0 & 0,88 \\
\hline Publicidade, Propaganda e Marketing & 0 & 0 \\
\hline Comunicação Científica e Ambiental & 0 & 0 \\
\hline Comunicação Educativa & 0 & 0 \\
\hline Comunicação, Turismo e Hospitalidade & $\mathbf{1 1 4}$ & $\mathbf{1 0 0}$ \\
\hline Total & & \\
\hline
\end{tabular}

Fonte: Correa e outros (2005, p. 6).

Vale dizer que foi utilizada a divisão temática proposta pela Intercom para a distribuição da tabela 1 . 
Primo e outros (2008, p. 6) realizaram um mapeamento das citações nos trabalhos da COMPÓs do encontro anual de 2008, mostrando importantes tendências na produção científica na área da Comunicação que nos auxiliam a entender melhor como o campo se organiza. No estudo, foram analisados 120 artigos do XVII Encontro da Associação Nacional dos Programas de Pósgraduação em Comunicação, tendo sido encontradas 2111 referências nos trabalhos. Apresentamos alguns resultados desse estudo que nos são úteis ao nosso foco de análise:

- os grupos de trabalho (válidos na época do estudo, sendo que atualmente são diferentes, conforme apresentamos acima) que tiveram mais trabalhos publicados foram: Comunicação e Cibercultura (221), Recepção, usos e consumo midiáticos (212), Comunicação e Sociabilidade (198) e Estudos de jornalismo (188);

- dos 120 artigos, 92 (76,6\%) foram escritos por apenas um pesquisador, $26(21,6 \%)$ por 2 autores e apenas $2(1,6 \%)$ por 3 autores;

- das referências realizadas, 1321 (62,58\%) foram escritas por autores estrangeiros, 783 (37,09\%) por autores nacionais e apenas 7 trabalhos combinavam autores nacionais e estrangeiros;

- das citações, 1217 (57,7\%) foram relativas a livros, 275 (13\%) a capítulos de livros, 297 (14,1\%) a artigos de periódicos e 107 (10,2\%) a trabalhos em anais;

- dos eventos da área referenciados nos trabalhos, 40,6\% se remetiam a COMPÓS e $25,7 \%$ a INTERCOM.

Ressaltamos dois pontos que são recorrentes nos estudos apresentados, sendo estes os mais expressivos que encontramos sobre o mapeamento da produção científica da área das Ciências da Comunicação no Brasil: a maioria dos artigos produzidos são feitos de forma individual e a abrangência de temas ou modos de descrever os temas evidencia essa fragmentação do campo na heterogeneidade de problemas que são abordados, além da falta de uma nomenclatura comum que sirva de referência para a área como um todo.

\section{Redes sociais de colaboração científica: uma breve revisão}

A maior sistematização e disponibilização em bases de dados de informações relacionadas à produção científica, tais como relações de coautoria, citação e co-citação entre artigos científicos, foi um dos elementos que tem impulsionado, desde o início dos anos 2000, a pesquisa sobre análise de redes sociais. Disciplinas como a cientometria, bibliometria e informetria, preocupadas 
com a sistematização de dados para seus estudos de interesse, terminaram por fornecer aquilo que faltava: grandes amostras de dados para testes e avaliação de novos métodos, experimentação de novos indicadores e, sobretudo, dados de referência para fomentar estudos comparativos.

Estudos pioneiros relacionando estrutura, dinâmica e propondo conjuntos de indicadores de referência para o estudo de redes formadas pela coautoria de pesquisadores em suas áreas do conhecimento foram publicados por Newman (2001,2001a, 2001b, 2004) e Barabási e outros (2002). As bases de dados analisadas pertencem a áreas como a biomedicina, física e ciência da computação. O interessante para nosso objeto de estudo é que sistematizaram um conjunto de indicadores que podem nos servir como parâmetro de comparação, mesmo considerando que a área da Ciência da Comunicação deve apresentar resultados que lhe são particulares, sobretudo por se tratar de uma área que apresenta uma dinâmica bastante diferente das Ciências Exatas.

Newman (2001, p. 405) utilizou os indicadores apresentados na tabela 2 como referência para a comparação entre as bases de dados de publicações científicas da Medline (biomedicina), biblioteca da preprints de Los Alamos (física teórica), SPIRES (física de alta energia) e NCSTRL (ciências da computação).

Tabela 2. Indicadores de redes de colaboração científica.

\begin{tabular}{|c|c|c|c|c|c|c|c|}
\hline \multirow{2}{*}{ Indicadores } & \multirow[b]{2}{*}{ MEDLINE } & \multicolumn{4}{|c|}{ Arquivo de e-prints - Los Alamos } & \multirow[b]{2}{*}{ SPIRES } & \multirow[b]{2}{*}{ NCSTRL } \\
\hline & & Complete & astro-ph & cond-mat & hep-th & & \\
\hline Total de artigos & 2.163 .923 & 98.502 & 22.029 & 22.016 & 19.085 & 66.652 & 13.169 \\
\hline Total de autores & 1.520 .251 & 52.909 & 16.706 & 16.726 & 8.361 & 56.627 & 11.994 \\
\hline Somente a primeira inicial & 1.090 .584 & 45.685 & 14.303 & 15.451 & 7.676 & 47.445 & 10.998 \\
\hline Média de artigos por autor & $6,4(6)$ & $5,1(2)$ & $4,8(2)$ & $3,65(7)$ & $4,8(1)$ & $11,6(5)$ & $2,55(5)$ \\
\hline Média de autores por artigos & $3,754(2)$ & $2,53(7)$ & $3,35(2)$ & $2,66(1)$ & $1,99(1)$ & $8,96(18)$ & $2,22(1)$ \\
\hline Média de colaboradores por autor & $18,1(1,3)$ & $9,7(2)$ & $15,1(3)$ & $5,86(9)$ & $3,87(5)$ & $173(6)$ & $3,59(5)$ \\
\hline Corte da curva exponencial & $5.800(1.800)$ & $52,9(4,7)$ & $49,0(4,3)$ & $15,7(2,4)$ & $9,4(1,3)$ & $1.200(300)$ & $10,7(1,6)$ \\
\hline Expoente $\mathrm{Y}$ & $2,5(1)$ & $1,3(1)$ & $0,91(10)$ & $1,1(2)$ & $1,1(2)$ & $1,03(7)$ & $1,3(2)$ \\
\hline Tamanho do maior componente & 1.395 .693 & 44.337 & 14.845 & 13.861 & 5.835 & 49.002 & 6.396 \\
\hline Somente a primeira inicial & 1.019 .418 & 39.709 & 12.874 & 13.324 & 5.593 & 43.089 & 6.706 \\
\hline$\%$ & $92,6(4) \%$ & $85,4(8) \%$ & $89,4(3) \%$ & $84,6(8) \%$ & $71,4(8) \%$ & $88,7(1,1) \%$ & $57,2(1,9) \%$ \\
\hline Tamanho do segundo maior componente & 49 & 18 & 19 & 16 & 24 & 69 & 42 \\
\hline Distância média entre os nós & $4,6(2)$ & $5,9(2)$ & $4,66(7)$ & $6,4(1)$ & $6,91(6)$ & $4(1)$ & $9,7(4)$ \\
\hline Distância geodésica & 24 & 20 & 14 & 18 & 19 & 19 & 31 \\
\hline Coeficiente de clusterização & $0,066(7)$ & $0,43(1)$ & $0,414(6)$ & $0,348(6)$ & $0,327(2)$ & $0,726(8)$ & $0,496(6)$ \\
\hline
\end{tabular}

Fonte: Newman (2001, p. 405).

Obs.: os dados entre parênteses são as medidas de erro padrão.

É interessante observar que Newman (2001) utiliza um conjunto de indicadores bibliométricos para caracterizar as bases de dados, tais como o total de artigos, total de autores, média de artigos por autores, média de 
autores por artigo e média de colaboradores por autor. A partir disso, apresenta os indicadores de corte da curva exponencial, que mostra o ponto em que as redes deixam de se comportar como de livre escala, o expoente $Y$ da curva de distribuição de graus de centralidade dos nós, o que permite caracterizar que tipo de rede de livre escala se trata, o tamanho do maior componente da rede (a maior estrutura de nós totalmente conectada, ou seja, existindo ao menos um caminho de conexão entre todos eles), o tamanho do segundo maior componente (a segunda maior estrutura de nós totalmente conectada), a distância média entre os nós (o quão próximo ou distantes se encontram em média), a distância geodésica (a maior distância entre dois nós) e o coeficiente de clusterização ou agrupamento (indicando o nível de coesão da estrutura geral da rede).

Os dados da tabela 2 apresentam os macroindicadores utilizados como referência para o estudo de redes sociais baseadas em dados de colaboração na produção científica. Os dados mostram diferentes padrões de comportamento entre as áreas, mostrando efeitos desses padrões em seus indicadores bibliométricos e características estruturais de como suas redes são constituídas, fornecendo evidências que diferentes estratégias de produção científica e características específicas de suas áreas do conhecimento podem ser avaliadas a partir desses dados. Por exemplo, numa primeira instância, Newman avalia que áreas com maior enfoque experimental, como a biomedicina (base Medline) e física de alta energia (base Spires) tendem a apresentar maiores médias de coautoria na publicação de trabalhos, o que acaba por impactar em maiores taxas de participação dos atores no componente principal da rede e menores distâncias médias entre os nós.

Valetambém citarmos o trabalho de Martins e outros (2010), que realizaram uma revisão das principais publicações que utilizaram alguns dos indicadores de referência apresentados por Newman na tabela 2, incluindo nesse estudo dados sobre áreas como administração e sociologia. Apresentamos os dados na tabela 3. 
Tabela 3. Indicadores de redes de colaboração científica

\begin{tabular}{|c|c|c|c|c|c|c|c|}
\hline & \multicolumn{2}{|c|}{ BRASIL } & \multicolumn{5}{|c|}{ INTERNACIONAL } \\
\hline & \begin{tabular}{|l|} 
GESTÃO DE \\
OPERAÇÕES $^{1}$
\end{tabular} & \begin{tabular}{|c|} 
ESTRATÉGIA \\
E ESTUDOS \\
ORGANIZACIONAIS \\
\end{tabular} & $\begin{array}{l}\text { ADMINIS- } \\
\text { TRAÇĀ̄o }\end{array}$ & MEDICINA $^{4}$ & FísICA $^{5}$ & $\begin{array}{c}\text { MATEMÁ- } \\
\text { TICA }^{s}\end{array}$ & SOCIOLOGIA $^{6}$ \\
\hline Período & $1997-2009$ & $1997-2005$ & $1980-2002$ & $\begin{array}{l}1995- \\
1999\end{array}$ & $\begin{array}{c}1995- \\
1999\end{array}$ & 1995-1999 & 1963-1999 \\
\hline $\begin{array}{l}\text { Total de } \\
\text { pesquisadores }\end{array}$ & 3.148 & 2.072 & 10.176 & 1.520 .251 & 52.909 & 253.339 & 197.976 \\
\hline $\begin{array}{l}\text { Média de laços por } \\
\text { autor }\end{array}$ & 2,52 & 2,25 & 2,86 & 16,93 & 9,27 & 3,90 & 1,88 \\
\hline $\begin{array}{l}\text { \% pesquisadores no } \\
\text { componente principal }\end{array}$ & $48,5 \%$ & $37,9 \%$ & $45,4 \%$ & $92,6 \%$ & $85,4 \%$ & $82,0 \%$ & $34,5 \%$ \\
\hline
\end{tabular}

Fonte: Martins e outros (2010).

É interessante notarmos a diferença na participação de pesquisadores no componente principal e na média de laços por autor, também fornecendo evidências de padrões de comportamento no nível da coautoria nessas áreas que são refletidos na estrutura de suas redes sociais, tornando a rede mais ou menos distribuída entre seus componentes. Esses indicadores nos chamam a atenção, pois denotam no caso da sociologia e das áreas ligadas à administração, redes mais dispersas, compostas por ilhas mais isoladas de relacionamento entre os pesquisadores.

Outros estudos utilizaram esses mesmos indicadores de referência, porém analisaram como os mesmos evoluíram, permitindo analisar mudanças de tendências e padrões nas áreas em intervalos de tempo específicos. Podemos citar como referência os trabalhos de Grossman (2002), estudando a evolução do grafo de colaboração de pesquisadores da área de Matemática, Moody (2004), estudando a evolução das redes de colaboração científica da área da sociologia, Lee e outros (2010), estudando a evolução das redes na área da física. O estudo da evolução das redes cria uma espécie de genealogia de sua constituição estrutural e dinâmica, permitindo apontar e demarcar eventos importantes, fatos que eventualmente modificam os rumos e pautam a formação dos padrões característicos de cada rede.

\section{Comparando as redes sociais acadêmicas das Ciências da Comunicação com outras áreas}

Apresentamos na tabela 4 os resultados de comparação de redes sociais acadêmicas de coautoria na produção de artigos em diferentes áreas do conhecimento a partir de diferentes bases de dados, utilizando como parâmetro de comparação os dados apresentados nas tabelas 2 e 3 . Vamos aqui 
nos valer desses resultados como forma de explicitar resultados empíricos que nos possibilitem discutir algumas das hipóteses desta pesquisa.

No entanto, vale destacar a dimensão e a representatividade da base de dados utilizada para comparar a área das Ciências da Comunicação com as outras áreas abaixo. Foi utilizado para essa pesquisa o portal Univerciencia. org para amostra do universo da Comunicação, fornecendo para a pesquisa 49 revistas científicas da área e mais de 9.800 artigos de onde coletamos os dados de relacionamento social de coautoria. A série histórica utilizada foi de 1969 a 2011.

Para efeito comparativo as séries históricas de outras áreas do conhecimento também foram desenvolvidas em diferentes períodos de tempo com diferentes amostras coletadas, não havendo um padrão único e uma normalização estatística entre os dados analisados. Sabemos que isso reduz o grau de precisão dos resultados, mas ainda assim nos permite colocar em debate os efeitos analíticos do que buscamos que é, sobretudo, contextualizar a área da Comunicação com a estrutura constituída de suas redes de colaboração.

\section{Tabela 4. Comparação entre indicadores de redes de diferentes áreas do} conhecimento.

\begin{tabular}{|c|c|c|c|c|c|c|c|c|c|}
\hline Indicadores & $\begin{array}{l}\text { Univerciencia.org } \\
\text { Comunicaçäo }\end{array}$ & $\begin{array}{c}\text { Medline } \\
\text { Medicina }\end{array}$ & $\begin{array}{l}\text { Spires } \\
\text { Fisica }\end{array}$ & $\begin{array}{c}\text { NCSTRL } \\
\text { Computação }\end{array}$ & Administração & Matemática & Sociologia & $\begin{array}{l}\text { Gestão de } \\
\text { Operaçöes }\end{array}$ & $\begin{array}{c}\text { Estratégia e } \\
\text { Estudos } \\
\text { organizacionais }\end{array}$ \\
\hline Artigos & \begin{tabular}{|c|}
9638 \\
\end{tabular} & 2163923 & 66652 & 13169 & - & - & - & - & - \\
\hline Co-autoria média & 1,4453 & 3,754 & 8,96 & 2,22 & 2,86 & 3,9 & 1,88 & 2,52 & 2,25 \\
\hline Nós em co-autoria & 4700 & 1520251 & 56627 & 11994 & 10176 & 253339 & 197976 & 3148 & 2072 \\
\hline Links & 8372 & - & - & - & - & - & - & - & - \\
\hline Densid ade média & 0,00076 & - & - & - & - & - & - & - & - \\
\hline \begin{tabular}{|l|} 
Componentes \\
\end{tabular} & 1111 & - & - & - & - & - & - & - & - \\
\hline$\%$ dos nós no maior componente & 11,89 & 92,6 & 88,7 & 57,2 & 45,4 & 82 & 34,5 & 48,5 & 37,9 \\
\hline Tamanho do maior componente & 559 & 1395693 & 49002 & 6396 & - & - & - & - & - \\
\hline \begin{tabular}{|c|} 
Tamanho do segundo maior componente \\
\end{tabular} & 78 & 49 & 69 & 42 & - & - & - & - & - \\
\hline \begin{tabular}{|l|} 
Grau de conectividade méd io \\
\end{tabular} & 3,56 & - & - & - & - & - & - & - & - \\
\hline Grau de centralização da rede & 0,0121 & - & - & - & - & - & - & - & - \\
\hline Maior grau de conectividade & 60 & - & - & - & - & - & - & - & - \\
\hline Menor grau de conectivid ade & 1 & - & - & - & - & - & - & - & - \\
\hline Distância geodésica & 13 & 24 & 19 & 31 & - & - & - & - & - \\
\hline Coeficiente de Clus terização & 0,6620 & 0,066 & 0,726 & 0.496 & - & - & - & - & - \\
\hline
\end{tabular}

Fonte: Martins (2012, p. 218).

Comentamos a seguir os principais indicadores que nos chamam atenção nessa comparação. De maneira geral, as amostras de dados variam bastante em termos de quantidade de documentos analisados e nós participantes das redes, evidenciando de início a dificuldade de compatibilizar esses dados e criar conjuntos de dados que pudessem ser formados a partir dos mesmos princípios e facilitassem estudos estatísticos e formas de comparação entre eles. Entendemos que essa característica denota o quanto este tipo de estudo ainda é novo na área acadêmica e o quão dependente estamos de boas e bem sistematizadas bases de dados para realizar análises desse tipo. Apesar disso, 
entendemos que esses resultados ainda fornecem importantes reflexões para esta pesquisa e para a discussão na pesquisa sobre redes sociais como um todo.

A coautoria média na área da Comunicação é a mais baixa de todas as áreas analisadas, estando mais próximo da Sociologia $(1,88)$ e mais distante da Física $(8,96)$. A coautoria média considera o total de artigos publicados e os divide pelo total de autores de cada artigo. Sabe-se que esse valor médio pode ter influência para cima por artigos com muitos autores e para baixo com muitos artigos com poucos autores. O fato de esse número ser o menor na comparação na área da Comunicação denota a posição dessa área como sendo de fato de mais baixa taxa de coautoria, logo de colaboração na escrita, entre as áreas comparadas.

Antes de prosseguirmos é importante entender o que significa um componente numa análise de rede social. Um componente simboliza um conjunto de nós onde qualquer nó possui ao menos uma conexão com qualquer outro nó do conjunto, ou seja, podemos considerar como sendo um grupo de nós que possui caminhos de conexão entre si, mesmo que sejam por intermédio de outros nós. É comum encontrarmos redes sociais que são formadas por mais de um componente, o que significa que há diferentes conjuntos de nós nessa rede que não possuem nenhuma conexão entre si. Configuram-se como verdadeiras ilhas isoladas de nós com suas conexões locais. Passando agora a análise de nossos resultados, a porcentagem de nós no maior componente apresenta uma das maiores diferenças observada entre todas as áreas. A Comunicação tem apenas em torno de $12 \%$ dos seus nós nesse componente, sendo que a rede com menor quantidade de nós na sequência seria a Sociologia, mas já com $34,5 \%$ dos nós. É um resultado que mostra um nível de agrupamento desses componentes bastante interessantes, deixando bem evidente uma fragmentação expressiva na área da Comunicação. Uma forma de interpretar esse resultado é entendendo que o maior componente deveria ser formado por uma grande quantidade de nós em uma rede de alta conectividade, pois os nós estariam de alguma maneira no mesmo conjunto de nós. Uma rede na qual o maior componente tem tão poucos nós denota claramente uma alta fragmentação desses nós em ilhas isoladas de conectividade, evidenciando o efeito de fragmentação nas relações sociais entre esses nós.

O coeficiente de clusterização leva esse nome na literatura técnica de análise de rede em língua portuguesa, mas deveria ser mais propriamente chamado de coeficiente de agrupamento. Ele indica o nível de transitividade na rede, ou seja, quantos casos existem na rede de um nó estar conectado com outros dois e esses nós também estarem conectados entre si havendo, dessa forma, uma transitividade de conexões entre eles. O coeficiente é bastante 
próximo entre as áreas da Comunicação, Física e Computação, sendo que a Medicina apresenta o menor em relação a todos os outros. Para interpretar esse resultado de forma a entendermos o comportamento da rede como um todo, precisamos levar em consideração qual a contribuição do maior componente da rede para o cálculo da transitividade. Nas redes de Medicina, Física e, até mesmo, Computação, o maior componente é muito mais expressivo em termos de participação relativa dos nós que compõem a rede, logo, podemos afirmar que a transitividade de nós na área da Física e Computação é consideravelmente maior que a Medicina, que parece apresentar um comportamento de alto nível de centralização de suas conexões. Quando analisamos no caso da Comunicação, o componente principal tem baixa influência na dinâmica da rede, logo, mesmo o coeficiente sendo alto, isso indica muito mais que nos fragmentos da rede há alta transitividade entre os fragmentos. Logo, a Comunicação parece mostrar alta fragmentação, mas fragmentos bem conectados e com transitividade de conexão entre os nós. São muitas ilhas onde localmente há indícios de colaboração.

\section{Conclusão: traços das redes sociais e encaminhamentos}

Realizamos aqui um mapeamento das principais linhas que permitem caracterizar o que é hoje a área da Ciência da Comunicação como campo do conhecimento no Brasil. Desde a percepção da formação da área, a distribuição de seus temas e objetos de interesse, bem como sua articulação conceitual nosso interesse tem sido observar quais são os traços dessa área que influenciam sua caracterização pela análise de suas redes sociais.

Entender como a área vem sendo construída no Brasil a partir de suas características institucionais, geográficas e de sua produção científica, dá o panorama geral por onde as redes de conversação dos pesquisadores têm produzido seus traços e seus modos de organização social como uma comunidade acadêmica. Não entendemos aqui que as redes são "influenciadas" por essas características e nem que as redes produzem essa visão macro da área. Entendemos aqui que estamos falando de dimensões entrelaçadas, camadas de rede que podem ser visualizadas a partir de diferentes pontos de vista e perspectivas analíticas, sendo nosso objetivo nesta discussão caracterizá-las.

Os dados que apresentamos neste artigo parecem confirmar o que as características da área denotam, sobretudo quando olhamos em comparação com outras áreas do conhecimento, mesmo outras relacionadas às ciências humanas. O que ali encontramos evidencia estratégias de conectividade entre os pesquisadores que demonstram de forma empírica essa baixa conectividade geral, alta fragmentação, formação de ilhas de articulação social e baixa 
articulação e transitividade global nas conexões. A falta de pontes entre muitas dessas ilhas para formar um componente principal mais expressivo mostra a baixa indução de colaboração e conversação entre esses pesquisadores em suas estratégias de produção científica. O que encontramos aqui denota muito menos um continente povoado e muito mais um conjunto de ilhas isoladas.

As características estruturais da rede social parecem muito compatíveis com as características que apresentamos neste artigo da própria área. Estamos diante aqui de um espelhamento entre fatores sociais e fatores relacionais. De maneira geral, entendemos que esses resultados parecem confirmar nossas duas hipóteses desta pesquisa, sendo a primeira relacionada ao fato de que ao entendermos melhor os fatores sociais que influem na constituição dos relacionamentos sociais que levam a formação de uma rede estaremos em melhores condições de explicar a própria rede, dado que conhecemos melhor a força que motiva, os projetos que estimulam e as situações pelas quais as relações se dão e a segunda que o modo como as relações sociais se constituem são elementos de observação que devem ser utilizados para observar esses dispositivos, o que chamamos acima da relação entre os regimes de verdade e os regimes de informação. As estratégias e práticas de produção informacional que são significativas para o jogo de sociabilidade de uma comunidade social parecem refletir e dar pistas sobre as próprias condições de formação dessa comunidade.

Em relação à primeira hipótese os dados e a análise apresentada evidenciam a relação direta entre os fatores sociais e a estrutura dos relacionamentos sociais. Conhecer esses fatores e conhecer a rede nos permite estabelecer conexões analíticas que parecem fornecer novos conhecimentos e formas de observar o fenômeno das redes e sua importância na análise das estratégias e práticas de grupos sociais.

Em relação à segunda hipótese percebemos que o uso de regimes de informação, ou seja, a análise das formas de produção informacional que sustentam a produção de narrativas, que levam a formação dos regimes de verdade de grupos sociais, parece aqui fornecer conhecimentos que facilitam entender como as relações sociais são desdobradas em estratégias e práticas de conectividade pautadas nas características que denotam formas de organização social desses grupos.

Por fim, temos por intenção avançar nessa pesquisa incorporando em estudos futuros outras técnicas analíticas de visualização das redes, formas dinâmicas de análise, equações estruturais e métodos de estatística multivariada de maneira a aprofundar nas relações causais que permitam explicar novos fatores e formas de constituição das redes sociais. 


\section{Referências}

ALVES, Aníbal. Ciências da Comunicação, Área Interdisciplinar. Comunicação e Sociedade. Cadernos do Noroeste, Série Comunicação, Braga, v. 12. p. 1-12. 1999.

BARABÁSI, Albert. , JEONG, Hawoong, NÉDA, Zoltán, RAVASZ, Erzsebet, SCHUBERT, Andras, VICSEK, Tamás. Evolution of the social network of scientific collaborations. Physica A: Statistical Mechanics and its Applications. Volume 311, Issues 3-4, p. 590-594, 2002.

CAPES.Tabela deárea de conhecimentos.2009.Disponívelem: $<$ http://www.capes.gov. br/images/stories/download/avaliacao/TabelaAreasConhecimento 042009. pdf >. Acesso em: 20 dez. 2015.

CAPES. Documento de área e comissão trienal 2013. Disponível em: $<$ http://capes. gov.br/images/stories/download/avaliacaotrienal/Docs de area/Ciencias Sociais Aplicadas doc area e comiss\%C3\%A30 16out.pdf.>. Acesso em: 20 dez. 2015.

CAPES. Documento de área 2007-2009. Disponível em: <http://capes.gov.br/images/ stories/download/avaliacao/SOC APLIC 07mai10.pdf>. Acesso em: $20 \mathrm{dez}$. 2015.

CORRÊA, Cynthia Harumy Watanabe, MESQUITA, Rosa Maria Apel, GALDINO, Karina, CRESPO, Isabel Merlo. Periódicos da Área de Comunicação: mapeamento da temática e autoria dos artigos. In: Congresso Brasileiro de Ciências da Comunicação, 28., 2005. Rio de Janeiro. Anais. São Paulo: Intercom, 2005.

FERREIRA, Sueli Mara Soares Pinto Ferreira, MORAIS, Maria Helena, MUCHERONI, Marcos, PEREZ, Josefina. Estudo sobre como autores de artigos de revistas de Ciências da Comunicação verbalizam seus objetos de estudos em termos de palavras chave. Em Questão. Porto Alegre, v. 15, n. 2, p. 151-167. jul/dez. 2009.

GROSSMAN, Jerrold W. The Evolution of the Mathematical Research Collaboration Graph. Proceedings of the Thirty-third Southeastern International Conference on Combinatorics, Graph Theory and Computing. Congressus Numerantium. Boca Raton, Flórida, Vol. 158. p. 201-212. 2002.

INTERCOM. Divisões Temáticas dos Grupos de Pesquisa. 2011. Disponível em: $<$ http://www.portalintercom.org.br/index.php?option=com content\&view=ar ticle\&id=270\&ltemid=91. $>$. Acesso em: 25 jun. 2011.

ISSLER, Bernardo. Objetos de pesquisa e campo comunicacional. In. Tensões e objetos da pesquisa em comunicação. WEBER, Maria Helena, BENTZ, lone, HOHLFELDT, Antonio (orgs.). Sulina. 2002. 
KUNT, Thomas Samuel. A estrutura das revoluções científicas. Perspectiva. 9a ed. 2005. 264p.

LEE, Deokjae, GOH, Kwang-II, KAHNG, Byungnam, KIM, Devksoov. Complete trails of co-authorship network evolution. Phys. Rev. n. 82. 2010. p. 026112-1 - 0261129.

LEYDESDORFF, Loet, PROBST, Carole, The delineation of an interdisciplinary specialty in terms of a journal set: The case of communication studies. Journal of the American Society for Information Science and Technology. v. 60, Issue 8, p. 1709-1718, August 2009.

LOPES, Luís Carlos, Ciências da comunicação, possibilidades e problemas. Ciberlegenda. Rio de Janeiro, v. 1, n. 3, p. 1-12, 2000.

MARTINS, Dalton Lopes. Análise de redes sociais de colaboração científica no ambiente de uma federação de bibliotecas digitais. 2012. 236fl. Tese (Doutorado em Ciência da Informação da Universidade de São Paulo) Programa de Pós-Graduação em Ciência da Informação da Universidade de São Paulo, São Paulo, 2012.

MARTINS, Guilherme Silveira, ROSSONI, Luciano, CSILLAG, João Mário, MARTINS, Michele Esteves, PEREIRA, Susana Carla Farias. Gestão de operações no Brasil: uma análise do campo científico a partir da rede social de pesquisadores. RAEeletrônica, v. 9, n. 2, Art. 8, jul/dez, 2010.

MELO, José Marques de. Ciências da Comunicação: Saga brasileira (1963-2013). Revista LatinoAmericana de Ciências de la Comunicación. São Paulo, v.10, n. 18, p.3045, enero/julio 2013.

MOODY, James. The Structure of a Social Science Collaboration Network: Disciplinary Cohesion from 1963 to 1999. American Sociological Review, v. 69, p. 213 -238, April, 2004. Disponível em: <http://dx.doi.org/10.1177/000312240406900204>. Acesso em 20 de dezembro de 2015.

NETO, Antônio Fausto. Condições da pesquisa em comunicação no Brasil. Revista Famecos. Porto Alegre. v.1. n. 5. p. 82-90. nov 1996.

NEWMAN, Mark E. J. The structure of cientific collaboration networks. PNAS, p. 404409, vol. 98, no. 2, January 16, 2001. Disponível em: <http://dx.doi.org/10.1073/ pnas.98.2.404>. Acesso em 20 de dezembro de 2015.

. Scientific collaboration networks: Network construction and fundamentals results. Physical Review E., volume 64, 2001 a.

Scientific collaboration networks: Shorthest paths, weighted networks and centrality. Physical Review E., volume 64, 2001 b. 
. Co-authorship networks and patterns of scientific collaboration. PNAS, vol 101. 2004.

PRIMO, Alex, STUMPF, Ida, CONSONI, Gilberto, SILVEIRA, Stefanie Carlan da. Análise de citações dos trabalhos da COMPÓS 2008. Revista da Associação Nacional dos Programas de Pós-Graduação em Comunicação. E-Compós, Brasília, v.11, n.3, p. 1-19, set/dez 2008.

SODRÉ, Muniz. Comunicação: Um caos criativo. LOGOS 37. Rio de Janeiro. v. 19. n. 2. p. 6-16, jul/dez. 2012.

TOFFOLI, Geni Aparecida, FERREIRA, Sueli Mara Soares Pinto Ferreira. Mapeamento da produção científica de pesquisadores brasileiros de Ciências da Comunicação: período de 2000 a 2009. Psicologia USP, São Paulo, v.1, n.22, p. 399-422. abriljunho 2011.

VASSALO DE LOPES, Maria Immacolata. O campo da Comunicação: Sua constituição, desafios e dilemas. Revista Famecos. Porto Alegre. v. 1, n. 30, p. 16-30, agosto 2006.

WEBER, Maria Helena; BENTZ, Ione; HOHLFELDT, Antonio. Introdução. In. Tensões e objetos da pesquisa em comunicação. WEBER, Maria Helena; BENTZ, lone; HOHLFELDT, Antônio. (orgs.). Sulina, 2002. 